\title{
Innovation Education of Advanced Vocational Technical Colleges Based on Mechanical Cases Analysis
}

\author{
Jitao $\mathrm{Du}^{1, \mathrm{a}}$ \\ ${ }^{1}$ Advanced Vocational Technical College ,Shanghai University of Engineering Science \\ Hongkou, Shanghai, China \\ adtjaster@126.com
}

\begin{abstract}
The keypoints of Made in China 2025 is to transform Creation-CHINA, Quality-CHINA, Products-CHINA from Made-CHINA, its core is Innovation and Talents with innovating consciousness. Advanced vocational education as one education mode takes on the significant role in cultivating innovation talents. In this paper, according to the characteristics of mechanical advanced vocational education colleges, the innovative consciousness, mechanical innovating product case, mechanical structure innovating case, mould structure innovating case were analyzed for exploiting student's innovative thinking and promoting the innovative talent cultivation. The result shows reference value for innovation ability cultivation of mechanical students.
\end{abstract}

Keywords: Innovation education, Innovation case, mechanical, Advanced Vocational education

\section{基于机械类创新案例分析的高等职业技术院校创新教育}

\author{
杜继涛 ${ }^{1, a}$ \\ ${ }^{1}$ 上海工程技术大学高等职业技术学院，虹口，上海，中国 \\ ajtjaster@126.com
}

中文摘要. 中国制造2025的核心是向中国创 造、中国质量、中国产品转变, 而转变的关键是 创新，创新的关键的是创新人才。高等职业 教育教育作为一种教育模式担负着培养创 新人才的重任, 根据机械类职业教育专业的 特点, 通过创意识、机械创新产品案例、机 械创新结构案例、模具结构创新案例着手分 析, 以开拓学生的创新性思维, 进而推动创 新型人才培养。其研究结果对机械类职业院 校的学生创新能力培养具有借鉴价值。
关键词:创新教育; 创新案例; 机械类; 高 等职业教育

\section{1. 引言}

中国制造业正处在由 “大” 到 “强” 的 关键阶段, 已有的发展条件是制造业转型的 基础。庞大的市场规模优势、完善的产业配 套优势、多层次的空间梯度优势、升级中的 消费需求优势, 这些优势内生于成长中的中 国市场, 是推动 “中国制造2025” 的核心自 发力量。中国制造2025是2015年3月5日，十 二届全国人大三次会议在人民大会堂举行 
开幕会, 国务院总理李克强作政府工作报告 上提出来的。日前印发《中国制造2025》部 署全面推进实施制造强国战略[1]。这是我 国实施制造强国战略第一个十年的行动纲 领。制造业是国民经济的主体, 是科技创新 的主战场, 是立国之本、兴国之器、强国之 基。当前, 全球制造业发展格局和我国经济 发展环境发生重大变化, 必须紧紧抓住当前 难得的战略机遇, 突出创新驱动, 优化政策 环境, 发挥制度优势, 实现中国制造向中国 创造转变, 中国速度向中国质量转变, 中国 产品向中国品牌转变。而这些转变都蕴含着 创新, 都离不开人类的创造性思维。正是由 于人的创造性思维, 才使今天的世界充满生 机和光辉。

职业教育作为高等教育的重要组成部 分, 经过短短的 20 年发展, 院校已接近 1200 所, 占整个高等教育的半壁江山, 已成为一 种新的教育模式。可以说, 职业教育是促进 国家现代化和产业转型的发动机, 是构建和 谐社会的润滑剂, 是打造世界制造中心的动 力源, 是实现中国制造2025的助推剂, 一句 话, 职业教育是提高国家核心竞争力的要素 [2]。如何有效培养和促使创新型人才的涌 现, 是教育工作者和全社会的共同责任。因 此, 在职业学校实施创新教育势在必行, 机 械类院校作为职业院校的重要组成部分, 在 推进产品、工艺、结构上享有独特的优势, 因此责任更为重大。为此, 文中通过机械类 创新案例分析, 以期待为职业院校的学生创 新意识培养提供参考和借鉴。

\section{2 机械类创新案例分析}

\section{1 创新意识培养}

创新人才必须拥有创新思维, 因此, 创 新型人才培养要全面提高学生的创新素质。 首先从思想上要重视, 养成人人都可以创新 的理念, 取缔职业院校难以创新的㽽疾 [3][4]。因此要从思想上重视、从能力上培 养, 让学生乐于接受新观念, 让他们相信自 己的直觉, 相信自己的能力, 并找寻创新的 灵感。学生的好奇心, 这是学生获得灵感 的思维途径[5]。通过创新素质教育, 进一
步激发学生的创新意识, 从而培养学生的创 新意识, 为创新设计奠定基础。

\section{2 机械创新产品案例}

案例 1: 能源短缺是一个世界性的问 题。随着我国经济的快速发展, 能源短缺问 题越来越成为社会关注的焦点。我国于 2008 年发布的《中华人民共和国节约能源法》中 已明确指出: “节约资源是我国的基本国策, 国家实施节约与开发并举、把节约放在首位 的能源发展战略 “。党中央和国务院已提出 了科学发展观并决定在今后很长时期内, 将 实施资源节约型、环境友好型和节能减排政 策。据了解, 国家发改委已决定从去年开始 逐年提高天然气等燃气资源的售价, 这就要 求我们必须重视天然气等各种燃气资源的 合理利用, 为保护生态环境和推进国家建设 事业的可持续发展作出这一代人应有的贡 献。

据国家有关部门和民间资料统计, 目前 我国城乡燃气灶具已日益普及，家用燃气 灶的使用量已达到亿台，这些灶具每年消 耗液化气、天然气的万吨或立方米以上，但 出于灶具热效率底有的不足低（有的不足 $50 \%$ ，燃烧不充分，导致能源极大的浪费。

因此, 提高燃气热效率, 具有节能、环 保型的燃气灶具必然是未来的趋势。本产品 主要针对目前燃气灶燃烧设计中存在灶头 和锅体之间距离恒定无法调节, 导致燃烧不 充分问题。设计了一种电机带动同步带, 引 导灶头上下移动以控制调节燃气灶, 进而调 节火苗和锅体之间的距离, 使燃烧更为充 分, 以达到节约燃气、提高燃烧效率的目的, 具体结构见图1和图2。 


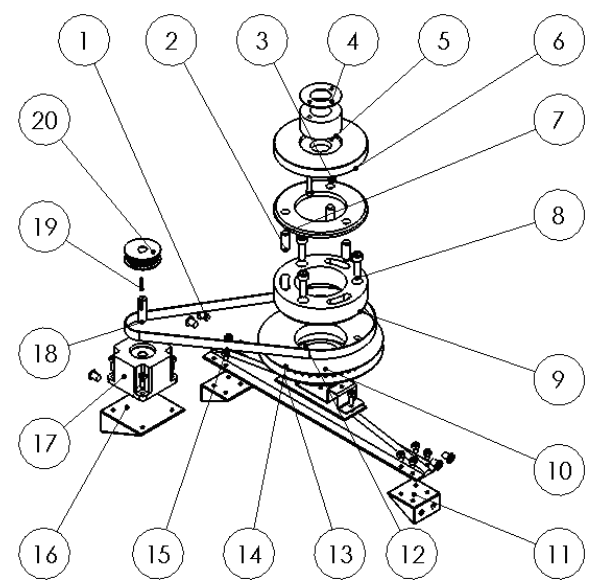

1 内六角螺钉, 2 升降杆, 3 内六角螺钉, 4 隔热片, 5 主管道, 6 传力盘, 7 限位盘, 8 内六角螺钉, 9 升降器, 10 大齿轮, 11 小 三脚架, 12 轴承, 13 钣金连接件, 14 工字梁, 15 齿轮皮带, 16 大三脚架, 17 伺服电机, 18 传动轴, 19-键, 20 小齿轮

图1 高度可调式电控节能燃气灶机构

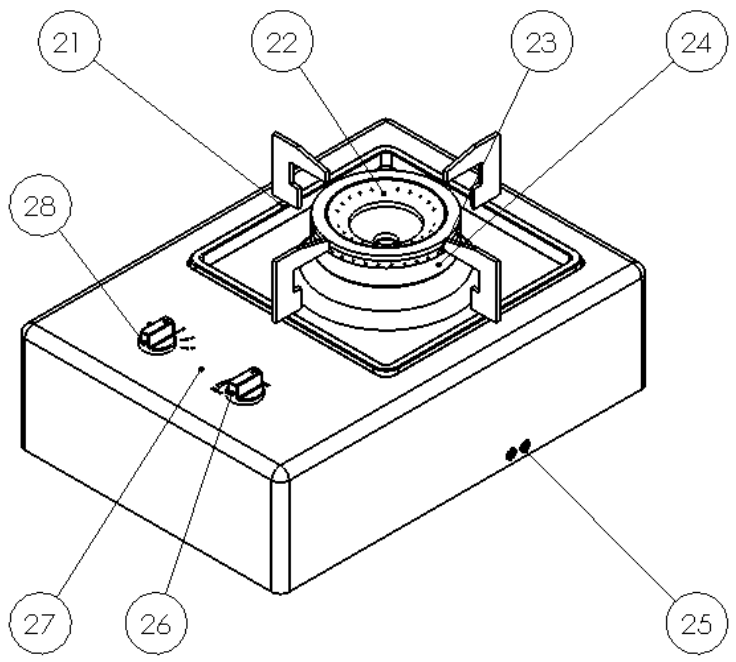

21 燃气灶支架, 22 内环分火器, 23 外环分火器, 24 分配器座, 25 内六角螺钉, 26 煤气开关, 27 燃气灶壳, 28 伺服电机开关

图2 高度可调式电控节能燃气灶外观

\section{3机械创新结构案例}

案例1: 多点钢珠凸模的拉深模具

目前在拉深模具中, 拉深凸模为刚性凸 模, 在拉深时板材的性能不能很好的发挥。 存在起皱和拉裂两种情况, 这样板材的极限 拉深深度就低。目前防止起皱最简单的方法 是采用压边圈, 防止拉裂的措施是减小拉深 时的变形抗力。而目前施加压边力的压边圈 通常有弹性压边装置和刚性压边圈。对于弹 性压边装置, 施加压边力的是弹性元件, 压 边力是线性变化的, 行程越大, 压边力越大, 当压边力过大时, 往往使工件被拉破; 对于 刚性压边装置, 由于该装置用于双动压力机
上, 在生产实际中比较麻烦。综上所述, 目 前的拉深模具存在以下问题:

(1) 拉深凸模为刚性凸模, 在拉深时 板材的性能不能很好的发挥;

（2）存在起皱和拉裂两种情况, 这样 板材的极限拉深深度就低。而目前施加压边 力的压边圈通常有弹性压边装置和刚性压 边圈。对于弹性压边装置, 施加压边力的是 弹性元件, 压边力是非线性变化的, 压边力 过大时, 对简单的圆筒件容易使工件拉破, 极限拉深深度小; 对于刚性压边装置, 由于 该装置用于双动压力机上, 在生产实际中比 较麻烦。

（3）目前的拉深模具是在冲压机床上 工作的, 冲压装置比较复杂。因此, 为了更 好的发挥材料的性能, 提高极限拉深深度, 简化拉深装置是十分重要的。

本机械结构就是为了克服上述现有技 术存在的缺陷而提供一种可使板材的性能 更好的发挥出来, 增加板材的极限拉深深 度, 而且结构简单的多点钢珠凸模的拉深模 具。

一种多点钢珠凸模的拉深模具, 其特征 在于, 该拉伸模具包括底座、与底座相连的 下模座、凹模、工件顶出机构、支撑柱、液 压缸支撑板、液压汽缸、凸模杆、氮气弹簧 件、压边圈及套筒, 所述的凹模设在下模座 上方, 所述的工件顶出机构与下模座连接, 所述的下模座通过设在下模座上部两侧的 支撑柱与液压缸支撑板连接, 所述的液压汽 缸设置在液压缸支撑板上方, 液压汽缸的活 塞杆穿过液压缸支撑板与凸模杆连接, 该凸 模杆上部侧壁对称设有延伸台, 延伸台下方 设有氮气弹簧托架, 该氮气弹簧托架下方依 次连接氮气弹簧件和压边圈, 压边圈呈环 状, 所述的凸模杆穿设在压边圈内环孔内, 所述的套筒设在压边圈与凸模杆之间, 该套 筒过盈配合在压边圈上, 具体结构见图3。 


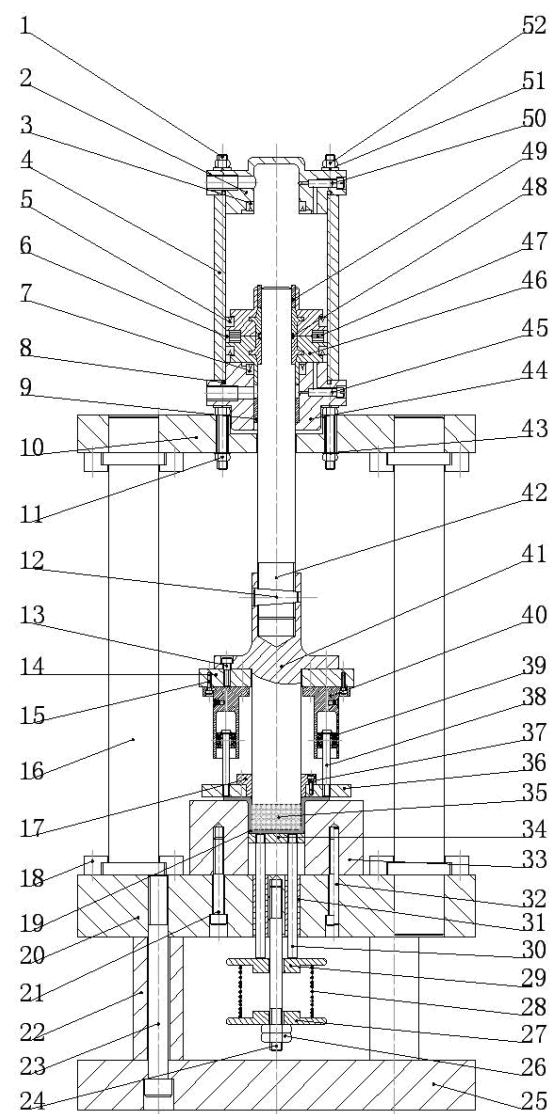

1螺栓杆 2 后缸盖 $3 、 5 、 7 \mathrm{Y}$ 型密封圈 4夜压缸缸筒 6 导向耐磨环 8、480型密封圈 9前导套 10 液压缸支撑板 $11 、 26 、 52$ 六角螺母 12 圆锥销 $13 、 15 、 21 、 23 、 37$ 内六角螺钉 14 氮气弹簧托架 16 支撑柱 17 套筒 18压板 19工件 20 下模座 22下模座垫套 24 拉杆 25 底座 27 弹簧下垫板 28 弹簧 29 弹簧上垫板 30 推杆 31导套 32圆柱销 33凹模 34顶件板 35钢珠与油的混合体 36 压边圈 38 氮气弹簧活塞杆 39 氮气弹簧活塞 40 氮气弹簧缸体 41凸模杆 42液压缸活塞杆 $43 、 51$ 弹簧垫圈 44前缸盖 $45 、 50$ 节流调节阀 46液压缸活塞47磁铁环49后导套。

图3 多点钢珠凸模的拉深模具

案例2: 简易旋转气缸简易旋转气缸

现在的直线运动气缸存在以下几个问 题: (1) 在工作中大部分气缸活塞杆只能 做直线运动; (2) 目前的旋转气缸结构比 较复杂，在制造时较麻烦; （3）目前的旋 转气缸价格较贵, 企业在购买气缸时花费较 多。

为此, 提出了以下方案: 用联接套筒 13 （如图纸）将气缸部分和滚珠丝杜部分联接起来, 活塞杆与丝杜通过螺纹连接, 再通过圆锥销 固定, 以保证活塞杆与丝杜整体在旋转时稳 定。丝杜的旋转会带动活塞杆的旋转, 因此 为了保证活塞杆的旋转稳定, 在两端各设计 一个滚动轴承。在右端施加油压时, 活塞会 带动活塞杆向前运动。由于活塞杆与丝杜之 间是刚性联接, 活塞杆就会推动丝杜向前运 动, 丝杜通过与滚珠丝杜螺母副通过滚珠和
斜旋槽（角度大约 40 度）会发生旋转运动。 在丝杜的前端设计了外螺纹和内螺纹, 以及 一块橡胶垫。在装配时, 若旋入外螺纹就选 择内螺纹; 若旋入内螺纹时就选择外螺纹, 旋入外螺纹时通过橡胶块的作用可以锁紧, 具体结构见图4。因此, 本简易旋转气缸不 仅可以解决目前气缸存在的问题, 提供了一 种新型的气缸, 而且本设计还可用于自动化 装配中。

\section{4模具结构类创新案例}

目前U型弯曲模具设计中存在以下问 题: 一是U型模具在工作时, 由于工件在流 入凹模的过程中会与凹模发生摩擦, 所以表 面会有刮伤等现象, 从而表面质量就差; 二 是由于凹模的尺寸不可以进行调节, 所以不 可以加工厚度不一的工件; 三是卸料的过程 中不能保证系统的稳定性, 从而会影响冲压 的有序进行; 四是现在的U型模具不能加工 出曲面U型工件, 就不能满足更高要求的工 作。因此，由于工件表面质量的问题使工件 不能满足于更加精密的工作要求; 凹模尺寸 不可以进行调节会增加制造模具的生产成 本; 而由于不能保证冲压的稳定进行; 生产 出的U型工件不能满足更高的工作要求。为 此, 提出了以下方案：（1）在板料流入凹 模的过程, 通过轴套的滚动摩擦代替原来的 滑动摩擦, 这样能够改善工件的表面质量。

(2) 采用可调节式凹模设计: 通过拧内六 


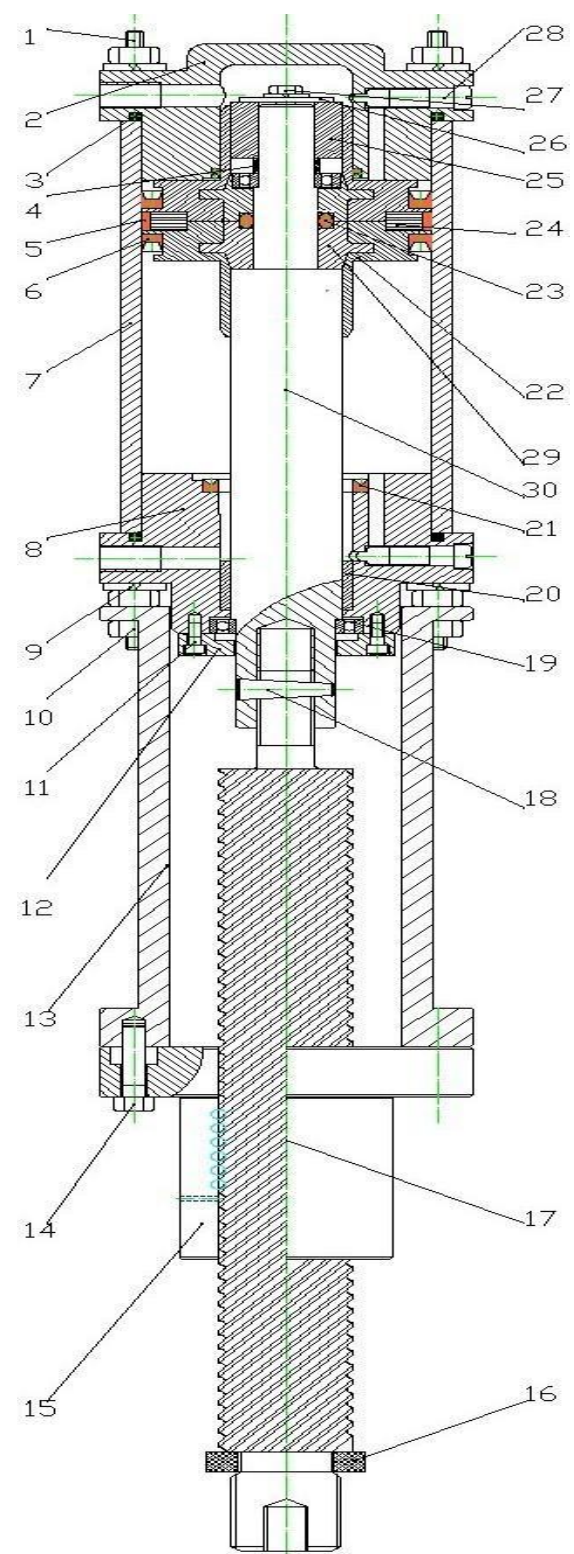

1一螺栓杆 2-后缸盖 3- $\mathrm{O}$ 型密封盖 4一轴套 5一导向环 6一活塞密封圈 7一缸筒 8一前缸盖 9-弹簧垫片 10-六角螺母 11一内六角螺钉 12-轴承盖 13-联接套筒 14一螺钉15一滚珠丝 杜螺母副16一橡胶垫 17-丝杠 18一圆锥筒 19-滚动轴承 20一前 导套 21-密封圈 22-缓冲柱塞 23-型密封圈 24一磁铁 25一 后导套 26一挡板 27一六角螺栓 28一缓冲节流阀 29一活塞 30 一活塞杆

图4 简易旋转气缸简易旋转气缸

角螺钉使楔形块运动, 这样可以改变凹模的 尺寸大小, 从而可以加工出厚度不一的工 件。（3）在卸料的过程中利用套筒的导向 作用, 来提高卸料的稳定性。（4）在凸模 和凹模上设计两根光轴, 在光轴上安装半径 不一的滚套, 凸模和凹模上的滚套的半径相 对应, 把工件的侧面加工成曲面, 具体结构 见图5。

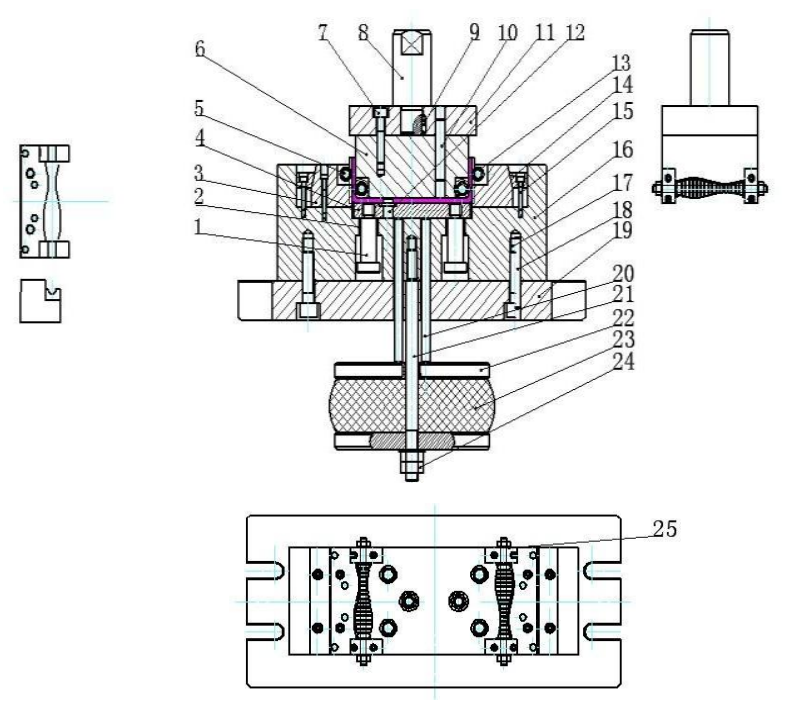

1卸料螺钉 2 导套 3 凹模 4卸料板 5轴 6凸模 7、15、17内六角螺钉 8 模柄 9 止转螺钉 10 圆柱销 11 上模座 12 挡料销 13 轴套 14 楔形块 16凹模座 18 销钉 19 底座 20 托杆 21 拉杆 22弹顶器托板 23 橡胶 24、25-螺母

图5 可调式精密曲面U型弯曲模

\section{3 结束语}

实施中国制造2025和创新教育是一项 长远的工程, 它需要克服传统的思维习惯, 要打破传统。在职业学校实施创新教育势在 必行, 机械类院校作为职业院校的重要组成 部分, 在推进产品创新、工艺创新、结构创 新上享有独特的优势, 本文通过已实施的机 械类创新产品、新结构、新型模具的案例分 析, 以期待为职业院校的学生创新意识培养 提供参考和借鉴。

\section{致谢}

本文获得上海工程技术大学教研项目

( No. A-2512-10-1308) 和 (No. A1-0601-15-0175)支持。

\section{References}

[1] http://news.china.com/domestic/945/20150 519/19710486 4.html

[2]Jitao Du. Driving by Innovation Mechanical Speciality Teaching Mode Reformation[C], International Conference Engineering and Business Managment, Shanghai ,March,2012, Vols.3, pp. 2077-2080,2012. 
[3]J.T. Du, M. Yang. Analysis of innovating education methods for advanced vocational colleges 2011 International Conference on Education and Education Mangement, pp:215-219,2011.

[4] H.SH. YAN. Based on Working Process of the Building Structure Course Construction, Journal of Chinese Vocational and Technical Education,No.23, pp:64-68,2013.

[5]Jitao Du. Consideration for Graduate Design Selecting Topics of Advanced Vocational Colledges[C], 2011 International Conference on Education and Education Mangement, pp. 220-223, 2011. 